\title{
Post-disaster assessment of landslides in southern Taiwan after 2009 Typhoon Morakot using remote sensing and spatial analysis
}

\author{
F. Tsai ${ }^{1,2}$, J.-H. Hwang ${ }^{2}$, L.-C. Chen ${ }^{1,2}$, and T.-H. Lin ${ }^{1}$ \\ ${ }^{1}$ Center for Space and Remote Sensing Research, National Central University, Zhong-Li, Taoyuan 320, Taiwan \\ ${ }^{2}$ Department of Civil Engineering, National Central University, Zhong-Li, Taoyuan 320, Taiwan
}

Received: 28 April 2010 - Revised: 26 September 2010 - Accepted: 30 September 2010 - Published: 19 October 2010

\begin{abstract}
On 8 August 2009, the extreme rainfall of Typhoon Morakot triggered enormous landslides in mountainous regions of southern Taiwan, causing catastrophic infrastructure and property damages and human casualties. A comprehensive evaluation of the landslides is essential for the post-disaster reconstruction and should be helpful for future hazard mitigation. This paper presents a systematic approach to utilize multi-temporal satellite images and other geo-spatial data for the post-disaster assessment of landslides on a regional scale. Rigorous orthorectification and radiometric correction procedures were applied to the satellite images. Landslides were identified with NDVI filtering, change detection analysis and interactive post-analysis editing to produce an accurate landslide map. Spatial analysis was performed to obtain statistical characteristics of the identified landslides and their relationship with topographical factors. A total of 9333 landslides ( 22590 ha) was detected from change detection analysis of satellite images. Most of the detected landslides are smaller than 10 ha. Less than 5\% of them are larger than 10 ha but together they constitute more than $45 \%$ of the total landslide area. Spatial analysis of the detected landslides indicates that most of them have average elevations between $500 \mathrm{~m}$ to $2000 \mathrm{~m}$ and with average slope gradients between $20^{\circ}$ and $40^{\circ}$. In addition, a particularly devastating landslide whose debris flow destroyed a riverside village was examined in depth for detailed investigation. The volume of this slide is estimated to be more than 2.6 million $\mathrm{m}^{3}$ with an average depth of $40 \mathrm{~m}$.
\end{abstract}

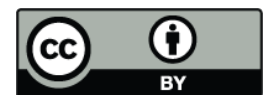

Correspondence to: F. Tsai (ftsai@ csrsr.ncu.edu.tw)

\section{Introduction}

Taiwan is an island located off East Asia coast on the edge of west Pacific and is prone to tropical cyclones and other extreme weathers. The craggy terrains and relatively fragile geological conditions in the mountainous regions of the island often result in serious floods and landslides induced by heavy precipitation of storms. On 8 August 2009, Typhoon Morakot enfolded Taiwan (Fig. 1). Although only approximately equivalent to a Category-2 hurricane on the SaffirSimpson Hurricane Scale, Morakot dumped record-breaking rains in southern Taiwan. It is believed that the extraordinary rainfall was caused by the combination of the typhoon system and the orographic factor. That is, the typhoon absorbed abundant water vapor while traveling across the Pacific ocean and it pulled in strong Southwest Monsoon from South China Sea. When the weather system hit the steep western slope of the Central Mountain Range in southern Taiwan, the dynamic processes of the typhoon produced heavy rainfall (Chang et al., 2010; Nguyen and Chen, 2010). As a consequence, although the typhoon made landfall in northeastern Taiwan, more than ten major weather stations in the southern part of the island recorded over $1000 \mathrm{~mm}$ cumulative precipitation in $24 \mathrm{~h}$.

The heavy rainfall triggered enormous landslides in mountains and hills and severe flooding in low-lying areas in southern Taiwan. The hazards destroyed or damaged houses, agricultural fields, roads, bridges, and other infrastructure facilities, causing massive economic loss and, more tragically, human casualties. An official report (NDPPC, 2009) indicated that there were 769 people dead or missing directly or indirectly caused by the typhoon. Among them, about 500 fatalities occurred in a riverside village called Xiaolin

Published by Copernicus Publications on behalf of the European Geosciences Union. 


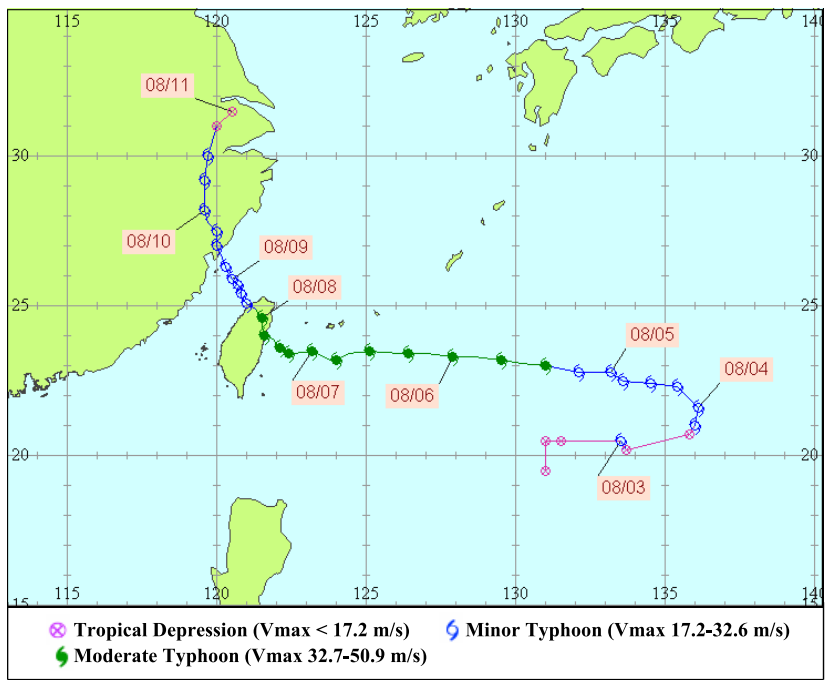

Fig. 1. Track of Typhoon Morakot (data source: Central Weather Bureau, Taiwan).

(Siaolin), where the entire village was destroyed by the debris flow from a devastating landslide nearby. After the catastrophe, the government set up a special committee for postdisaster relief, mitigation and reconstruction. One of the top priority tasks of the committee is to obtain an overall assessment of the disaster.

For the investigation of natural hazards, remote sensing is an effective and relatively economical data source. In particular, it can overcome the obstacles of ground transportation and difficult terrain conditions to provide comprehensive information about land-cover changes and other critical factors for disaster assessment. It is also possible to provide data in a short time and to cover large areas. Remote sensing techniques have been successfully applied to landslide investigations and related studies (e.g., Metternicht et al., 2005; Nichol and Wong, 2005; Peduzzi, 2010; Sarkar and Kanungo, 2004). It is essential to develop a practical hazard assessment system for decision and policy support in disaster mitigation and reconstruction. However, different regions and datasets have their unique characteristics and may need different strategies for the processing and analysis. This study utilizes remote sensing and spatial analysis to identify and analyze landslides induced by Typhoon Morakot in southern Taiwan. The objective is twofold. On the one hand, it is to obtain a comprehensive post-disaster inventory and assessment of landslides for the rehabilitation of the area. The data should also be helpful for hazard mitigation, such as developing effective engineering strategies to reduce risks of further damages to the roads and bridges and a reservoir downstream. On the other hand, it is to establish a framework of large-scale hazard investigation using geo-spatial data and related technologies.



Fig. 2. Study area.

\section{Study site and materials}

Figure 2 shows an image map of the study site, which is located in southern Taiwan. The study site covers the watersheds of two rivers, Nanzixian and Laonong. Both rivers run approximately from north to south and merge with Kaoping River, which flows toward the west and into Taiwan Strait. The total area of the study site (red polygon in Fig. 2) is about 250000 ha and comprised of rugged terrains. The elevation within the study site ranges from 55 to $3941 \mathrm{~m}$ a.s.l. Forest is the primary land-cover type, but there are limited agricultural lands, too.

The region is probably the most battered during Morakot's impact. The image in Fig. 2 is a mosaic of satellite images acquired before the typhoon. There are dispersed existing landslides which appear as gray or dark brown spots in Fig. 2, but may be difficult to see in the figure. Most of the existing landslides were caused by Typhoon Sinlaku on 14 September 2008. However, examining the post-disaster image map covering the same area (Fig. 3), landslides are almost ubiquitous in the image. Figure 4 displays a typical scene within the study site cropped from a post-disaster satellite image. In the figure, scars of landslides are evident on the verdant landscape. 


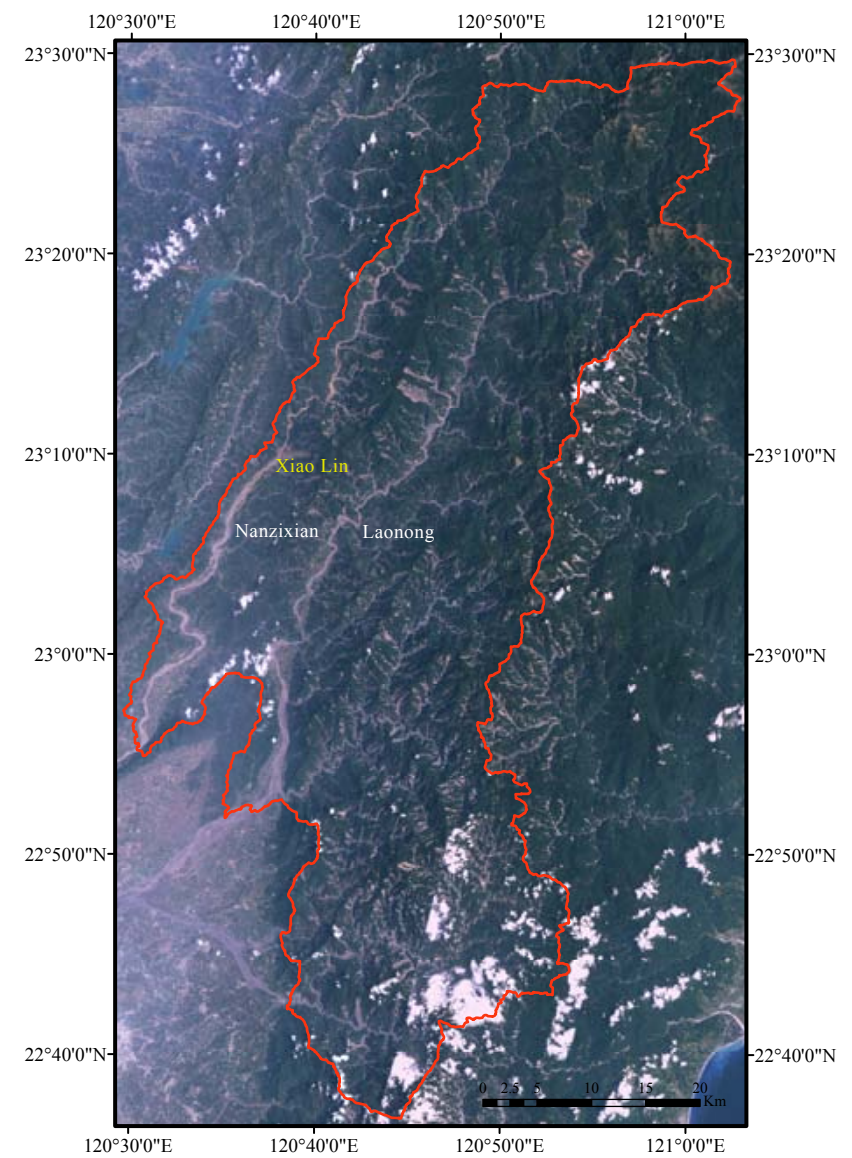

Fig. 3. Post-disaster image map of the study area.

The primary materials utilized in this study for landslide assessment are Formosat-2 satellite images. Formosat-2 is a sun-synchronous earth resource satellite operated by the National Space Organization of Taiwan. Formosat-2 has a geosynchronous orbit at the altitude of $891 \mathrm{~km}$ with a $99.10^{\circ}$ inclination. The orbiting period is 14 revolutions per day. It can also be tasked for cross-track or along-track (forward and aft) viewing up to $45^{\circ}$ for stereo imaging or to cover more ground areas during a single pass. A uniqueness about Formosat-2 is its daily revisit capability, so it is a convenient data source for hazard evaluation and monitoring applications. Formosat-2 imagery consists of a panchromatic (PAN) and four multi-spectral (MS) bands. The basic specification of Formosat-2 images is listed in Table 1. Several Formosat2 images acquired before and after Typhoon Morakot were collected for change detection analysis to identify landslides in the study site. Because Formosat-2 has a relatively narrow $(24 \mathrm{~km})$ imaging swath, it requires at least two image strips to cover the entire study site. Accordingly, two images acquired on 14 and 15 January and two images acquired on 17 August 2009 were selected as the main dataset for comparison. Images acquired on nearby dates were also used to compensate areas covered by clouds and shadows in the main dataset.

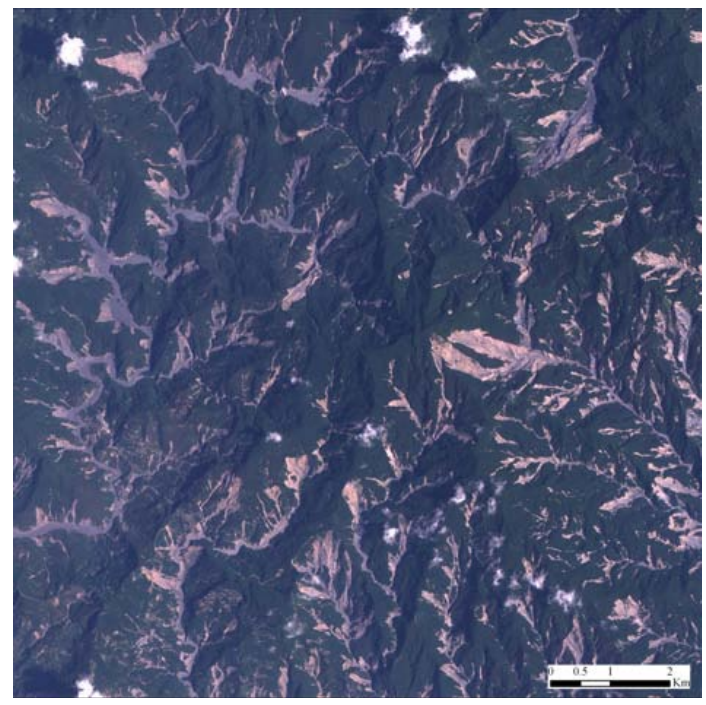

Fig. 4. An enlarged area of a post-disaster satellite image.

Table 1. Specification of Formosat-2 imagery.

\begin{tabular}{lll}
\hline Image Swath & Ground Resolution & Spectral Bands \\
\hline $24 \mathrm{~km}$ & $2 \mathrm{~m}$ (PAN) & $450 \sim 900 \mathrm{~nm}$ (PAN) \\
& $8 \mathrm{~m}$ (MS) & $450 \sim 520 \mathrm{~nm}$ (Blue) \\
& & $520 \sim 600 \mathrm{~nm}$ (Green) \\
& $630 \sim 690 \mathrm{~nm}$ (Red) \\
& & $760 \sim 900 \mathrm{~nm}$ (NIR) \\
\hline
\end{tabular}

Other data used include high-resolution aerial photographs, digital elevation models (DEM) and large-scale vector maps of the study site. The aerial photographs were collected after the typhoon and cover only a small portion of the study area. They were primarily used to evaluate the landslide detection results of satellite image analysis and to study the disaster in Xiaolin thoroughly. The pre-disaster DEM data were produced from previous aerial surveys. The original ground resolution of the pre-disaster DEM is $40 \mathrm{~m}$ by $40 \mathrm{~m}$, but the data were resampled to $8 \mathrm{~m}$ by $8 \mathrm{~m}$ grids to be consistent with the spatial resolution of satellite images. Both the DEM and vector maps were used to facilitate landslide identification and analysis. A high-resolution $(5 \mathrm{~m}$ by $5 \mathrm{~m}$ ) pre-disaster DEM of the Xiaolin disaster site was also obtained to be compared with the post-disaster DEM generated from the aerial photographs.

\section{Data processing and analysis}

\subsection{Image orthorectification}

Geo-referencing algorithms of satellite images based on image registration or system geometric correction usually do not take the terrain effect into account and are not adequate for correcting incline and relief displacements. This 
can cause substantial positioning errors in mountainous regions when overlaying the image with maps and other spatial data. Therefore, a rigorous geometric correction procedure derived from previous studies (Chen and Teo, 2002; Chen et al., 2005) were employed to orthorectify all satellite images used in this research. Because the FOV (Field of View) of Formosat-2 is small $\left(1.5^{\circ}\right)$, there is very high correlation between the two sets (position and attitude) of orbital parameters. Consequently, these parameters can be iteratively corrected with few ground control points (GCP) and achieve high positioning quality (Chen and Chang, 1998; Toutin, 2003). The process involves corrections of the sensor orbit model and backward projection. The orbit correction is based on provided satellite ephemeris data and an established GCP database (Rau et al., 2003), in which most of the GCPs are highway intersections, bridges, dams or invariant river junctions. The general procedure is separated into four steps including: (1) orbit correction (position and attitude); (2) error vector calculation with ( $40 \mathrm{~m}$ by $40 \mathrm{~m})$ DEM and ray tracing; (3) least-squares collocation refinement; and (4) backward projection and resampling for the generation of orthoimages.

The relationship between the satellite position, $\boldsymbol{P}$, and a GCP, $\boldsymbol{G}$, can be described as Eq. (1) in the WGS84 coordinate system.

$\boldsymbol{G}-\boldsymbol{P}=\boldsymbol{S U}$

where $\boldsymbol{U}$ is the unit observation vector and $S$ is the scaling factor. The satellite attitude (orientation) can be modeled by the rotation angles about the three coordinate axes. Assume the rotation angles are cubic polynomial functions of time, $t$; they can be represented as

$$
\begin{aligned}
& \omega_{t}=\omega_{0}+\omega_{1} t+\omega_{2} t^{2}+\omega_{3} t^{3} \\
& \phi_{t}=\phi_{0}+\phi_{1} t+\phi_{2} t^{2}+\phi_{3} t^{3} \\
& \kappa_{t}=\kappa_{0}+\kappa_{1} t+\kappa_{2} t^{2}+\kappa_{3} t^{3}
\end{aligned}
$$

where the three Euler angles, $\omega, \phi, \kappa$, are the rotation angles about X, Y, and Z axes, respectively. Accordingly, Eq. (1) is rewritten as

$\boldsymbol{G}-\boldsymbol{P}=S \cdot M_{\mathrm{Z}}\left(\kappa_{t}\right) \cdot M_{\mathrm{Y}}\left(\phi_{t}\right) \cdot M_{\mathrm{X}}\left(\omega_{t}\right) \cdot \boldsymbol{U}$

where $M_{\mathrm{X}}, M_{\mathrm{Y}}$ and $M_{\mathrm{Z}}$ are rotation matrices about the three axes. Similarly, the satellite position is corrected by the following equations:

$\boldsymbol{G}-\left(\boldsymbol{P}+\Delta \boldsymbol{P}_{\boldsymbol{t}}\right)=S \boldsymbol{U}^{\prime}$

where $\boldsymbol{U}^{\prime}$ is the unit observation vector after attitude correction and $\Delta \boldsymbol{P}_{\boldsymbol{t}}$ is the correction vector of the orbit position, which is modeled as a linear equation of time, $t$, as described in Eq. (7).

$$
\Delta \boldsymbol{P}_{\boldsymbol{t}}=\left[\begin{array}{c}
X_{0}+X_{1} t \\
Y_{0}+Y_{1} t \\
Z_{0}+Z_{1} t
\end{array}\right]
$$

The provided satellite ephemeris usually has high relative precision but with low absolute precision. Therefore, using GCPs can minimize the systematic errors of orbit and attitude parameters. The next step is to apply least-squares collocation refinement (Mikhail and Ackerman, 1982) to further eliminate local errors. Least-squares adjustment requires GCPs as reference points. Because multi-strip images are involved, in addition to GCPs of individual image strips, elevation tie points (ETP) in across-strip overlapped regions are also selected for better corrections. The corresponding ground intersection point of each observation vector can be obtained based on the corrected satellite orbit in conjunction with DEM using ray tracing techniques. As a result, the GCPs and ETPs are used in the following least-squares adjustment equation:

$\rho_{k}=\boldsymbol{v}_{k}\left[\Sigma_{k}\right]^{-1} \boldsymbol{\varepsilon}_{\boldsymbol{k}} ; k=\mathrm{X}, \mathrm{Y}, \mathrm{Z}$

where $\rho_{k}$ is the correction value of the intersection point after least-squares filtering; $\boldsymbol{v}_{\boldsymbol{k}}$ is the covariance of the intersection point with respect to each GCP; $\Sigma_{k}$ is the covariance matrix for each pair of GCPs; and $\boldsymbol{\varepsilon}_{\boldsymbol{k}}$ is the residual.

After the corrections, the position, attitude and observation vectors of the satellite are determined, and the image is ready for orthorectification by backward projection and resampling, which have been demonstrated to have better performance than conventional ray tracing models (Chen et al., 2005; Kim et al., 2001). Given a ground point, $P$, a vector, $v(t)$, can be constructed from $P$ to its corresponding image point. Let $\boldsymbol{n}(\boldsymbol{t})$ be the normal vector of the principle plane where $\boldsymbol{v}(\boldsymbol{t})$ locates, so that at time $t$,

$F(t)=\boldsymbol{v}(t) \times \boldsymbol{n}(t)=0$.

The nonlinear equation can be solved by Newton-Raphson method:

$t_{n+1}=t_{n}-\frac{F\left(t_{n}\right)}{F^{\prime}\left(t_{n}\right)}=t_{n}-\frac{F\left(t_{n}\right)}{\left[F\left(t_{n}+\Delta t\right)-F\left(t_{n}-\Delta t\right)\right] / 2 \Delta t}$

where $n$ is the number of iterations and $\Delta t$ is the sampling time of a scanline. Then, a resampling by cubic convolution is applied to produce the orthorectified image. The process is done with a patch projection scheme (Chen et al., 2005) to facilitate the computation. Detail descriptions and discussions of the rigorous orthorectification can be found in Chen and Teo (2002) and Chen et al. (2005) and are not repeated here. With the rigorous orthorectification, high precision geometric corrections of the satellite images can be achieved. Table 2 lists the orthorectification errors evaluated with 32 to 62 independent check points (ICPs) for the four primary Formosat-2 multi-spectral images used in this research. As demonstrated in the table, the RMSEs (root-mean-square errors) of the orthorectification were controlled to be less than one pixel. 
Table 2. Evaluation of orthorectification results (unit: $\mathrm{m}$ ).

\begin{tabular}{llcllll}
\hline Image_ID & Date & MEAN_E & MEAN_N & RMSE_E & RMSE_N & ICPs \\
\hline P5497 & 14 Jan 2009 & 0.16 & -1.63 & 3.19 & 4.12 & 49 \\
P5466 & 15 Jan 2009 & -0.16 & 0.86 & 2.15 & 3.81 & 62 \\
P6669 & 17 Aug 2009 & 0.5 & 2.6 & 3.06 & 5.48 & 58 \\
P6662 & 17 Aug 2009 & 1.22 & 1.15 & 4.76 & 3.84 & 32 \\
\hline
\end{tabular}

Table 3. Spectral bandwidth (SB) and solar irradiance (SI) of Formosat-2 multi-spectral imagery.

\begin{tabular}{lrrcc}
\hline & Blue & Green & Red & \multicolumn{1}{c}{ NIR } \\
\hline $\mathrm{SB}(\mu \mathrm{m})$ & 0.07 & 0.08 & 0.06 & 0.14 \\
$\mathrm{SI}\left(\mathrm{W} / \mathrm{m}^{2}\right)$ & 136.7 & 147.6 & 93.2 & 148.8 \\
\hline
\end{tabular}

\subsection{Radiometric correction}

All satellite images used in this study were also subject to radiometric corrections in order to reduce the radiometric variations caused by illumination and other factors in the satellite images. The objective was to minimize errors in vegetation index calculation and change detection analysis as described in the next session. The procedure adopted for radiometric correction includes: (1) converting image digital numbers to apparent reflectance (Anderson and Milton, 2005; Gomez et al., 2005; Li and Niu, 2006); and (2) radiometric normalization (Canty et al., 2004; Du et al., 2002).

In this study, the reflective radiance, $R_{\mathrm{r}}$, of the Formosat-2 images was converted from the original digital numbers (DN) and provided sensor calibration factors (gain and offset) as:

$$
R_{\mathrm{r}}=\mathrm{DN} \cdot \text { Gain-Offset. }
$$

The apparent reflectance, $R_{\mathrm{a}}$, was calculated from

$$
R_{\mathrm{a}}=\frac{R_{\mathrm{r}} \cdot \pi \cdot \mathrm{SB}}{\mathrm{SI} \cdot \cos (\theta)}
$$

where SB is the spectral bandwidth and SI is the exoatmospheric solar irradiance; and $\theta$ is the solar zenith angle. The values of SB and SI of all multi-spectral Formosat- 2 bands are listed in Table 3.

After converting all image data into apparent reflectance, radiometric normalization was further applied to images covering the same area. The normalization is based on pseudoinvariant features that can be selected interactively (Schott et al., 1988) or according to statistic characteristics (Du et al., 2002) calculated from the images. In this research, instead of processing only the study area, the radiometric corrections were carried out over the complete images. The features for normalization were manually selected from pure pixels of built-up areas, highways and large parking lots, water body, bare ground, and dense forest. The radiometric correction and normalization produced consistent results of study images since most of the study site is covered by dense forest other than landslide areas or rivers.

\subsection{Landslide detection}

The landslides were identified with a change detection procedure. General change detection analysis usually involves comparing multi-temporal images to identify changes of different land-cover types. However, the objective of change detection in this study is to identify landslides. Therefore, the procedure is formulated specifically for the quick and accurate detection of landslides. The procedure includes NDVI (Normalized Difference Vegetation Index) filtering, change vector analysis (Kasischke, 1998; Lambin and Strahlers, 1994), and interactive spatial analysis. Since the study site is mostly covered in forest, landslides are likely to exhibit significant vegetation changes in the satellite images. In this regard, NDVI should be an effective parameter for identifying vegetation changes and thus detecting landslides (Peduzzi, 2010). However, instead of treating NDVI as one of the features for general image classification or change detection, it was analyzed independently in this research. Therefore, preliminary landslide candidates were first automatically identified by comparing the NDVI values. The criteria for identifying possible landslides were defined as:

$\mathrm{NDVI}_{\text {pre }}-\mathrm{NDVI}_{\text {post }} \geq 0.3 \wedge \mathrm{NDVI}_{\text {post }} \leq 0.1$

where $\mathrm{NDVI}_{\text {pre }}$ and $\mathrm{NDVI}_{\text {post }}$ are NDVI values of the preand post-disaster images, respectively. The thresholds $(0.3$ and 0.1) in Eq. (13) were determined based on previous experiences (Tsai and Chen, 2007), which also dealt with identifying landslides in a watershed area with similar land-cover and terrain conditions. Theoretically, the normalization of image radiometry can affect the selection of the thresholds, so they might need to be fine-tuned empirically according to calculated NDVI values of individual scenes. However, as mentioned previously, the normalization variations of the images to analyze in this study were not substantial. In addition, the NDVI filtering was considered a fast but only preliminary detection of landslides. Therefore, threshold adjustment was not pursued.

Landslide candidates recognized by NDVI filtering were then integrated with the results of change vector analysis. 
Change vector analysis (CVA) identifies changed and unchanged pixels in multi-temporal images based on spectral change vectors calculated from different bands, which may be able to detect possible landslides not clear in NDVI filtering. In this research, the principle of NDVI filtering and CVA integration was to minimize omission error. Therefore, a spatial Boolean union operation was performed to combine the NDVI filtering results and changed pixels identified as possible landslides from CVA.

The combined result was overlaid with other spatial datasets, such as DEM and large-scale topographic maps, for interactive interpretation and editing, analysis, and assessment. The purpose of this step was: (1) further minimizing omissions of the automatic landslide detection to supplement the inventory; (2) eliminating commissions; (3) producing a vector map of identified landslides; and (4) conducting landslide assessment and spatial analysis with topographic factors. For example, false positive landslides resulted from the widening of riverbeds were eliminated by difference set operations between the landslide candidates and buffers of stream networks. The result was also examined thoroughly using the pre- and post-disaster images as references and edited to produce a complete landslide map of the study site. For instance, there may be ambiguities along the boundaries of landslides, especially near existing stream channels or shadows in the images. In these cases, the landslide polygons would be interactively adjusted based on visual interpretation and comparison with available datasets.

\subsection{Spatial analysis and statistics}

Detected landslides were collected and cataloged to form a landslide inventory. Spatial statistics and analysis were performed to extract characteristics of the collected landslides overlaid with other spatial datasets. The analysis was carried out in a GIS (Geographic Information Systems) system. Previous studies suggested spatial analysis of landslides on topographic, geological and land-use factors (Ayalew and Yamagishi, 2005; Lee et al., 2009; Ohlmacher and Davis, 2003; Zhou et al., 2002). In this research, due to the lack of adequate geological data and the simple land-use type (forest) of the study site, the focus of spatial analysis was placed on statistical characteristics of detected landslides and their relationship with topographic factors. Therefore, in addition to the assessment of basic landslide characteristics, topographic factors such as elevation, slope gradient and aspect etc. were also analyzed to identify possible correlations between the landslides and topographic factors. The topographic factors were derived from DEM of the entire study area using the built-in sub-watershed analysis function of the GIS system. Additional topographic analysis with multitemporal DEMs of higher resolution ( $5 \mathrm{~m}$ by $5 \mathrm{~m}$ ) and threedimensional (3-D) visualization were also applied to the investigation of the Xiaolin landslide site to better understand this particular case. Another spatial analysis performed in

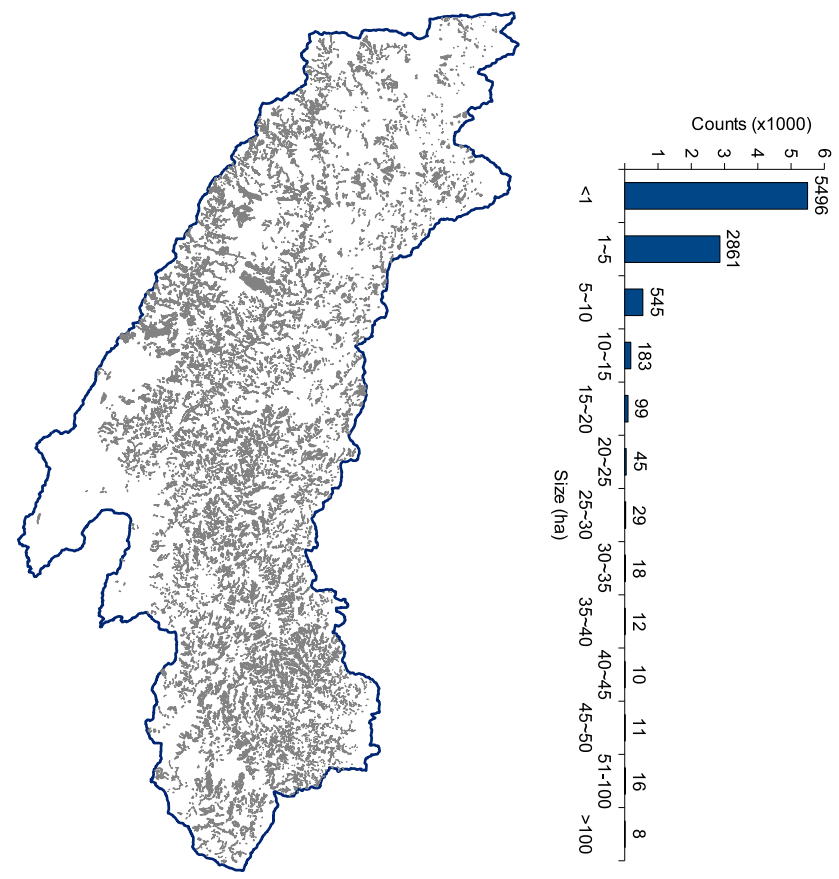

(a) landslides map

(b) landslide size histogram

Fig. 5. Identified landslides after Typhoon Morakot and histogram of landslide size (area).

this research was watershed delineation analysis to construct drainage networks of the site and to categorize whether a landslide was caused by headward erosion.

\section{Results and discussions}

A total of 9333 landslides were detected after Typhoon Morakot in the study site as plotted in Fig. 5. As displayed in the figure, the landslides spread throughout most of the watershed and seem to follow drainage patterns formed naturally from the terrain topography within the study site. This can be observed more clearly in Fig. 4 as most of the landslides in the figure look like stream networks. The total area of identified landslides is approximately $22590 \mathrm{ha}$. The area of landslide was counted directly from satellite image pixels. It did not take the terrain slope effect into account, nor did it distinguish between sliding and resting zones. The detected landslides were verified with available post-disaster aerial photographs. The evaluation indicated that the omission error of landslide detection is $9 \%$ and the commission error is 16\%. An example of the verification is displayed in Fig. 6, where the background is an orthorectified aerial photograph and the polygons are boundaries of landslides detected from satellite images. As can be seen in Fig. 6, most of the omissions are from small and isolated landslides. Given that the spatial resolution of Formosat-2 imagery is much broader than the aerial photograph, these small landslides would be 


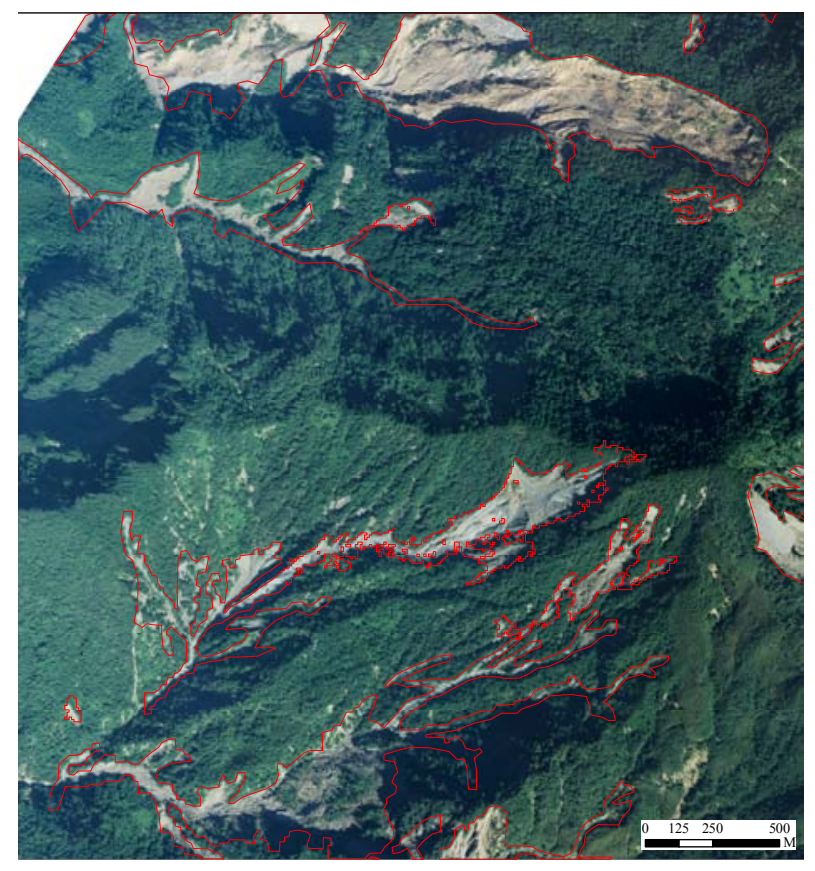

Fig. 6. Verification of detected landslides with aerial photograph.

difficult to detect in the satellite images. On the other hand, a majority of false positives seems to be along the polygon boundaries or intact pixels inside landslides. These areas are likely mixed pixels in the satellite images and become ambiguous in landslide detection.

Most of the detected landslides are small-scale in terms of size (area). In fact, about $60 \%$ of the landslides are smaller than $1 \mathrm{ha}$; and $95 \%$ of the landslides are smaller than $10 \mathrm{ha}$, as indicated in the bar chart of Fig. 5b. There are less than 5\% of landslides with an area greater than $10 \mathrm{ha}$ (with the largest being $384 \mathrm{ha}$ ), but together they constitute more than $45 \%$ of the total landslide area. The third largest landslide is the one that caused the disastrous annihilation of Xiaolin as discussed later. Among the identified 9333 landslide sites, about $78 \%$ (7289) are newly developed ones; and 22\% (2044) are extensions from old landslides. There are 2804 old landslides within the study site identified from the images acquired before Typhoon Morakot. Most of them (2272) get worse after the typhoon; only 532 old landslides are not affected. The total expending area of old landslides is $6552 \mathrm{ha}$, which contributes to $29 \%$ of the cumulative area of new landslides induced by Morakot.

Previous studies indicated that landslides triggered by heavy rainfalls in the mountainous regions seemed to have strong correlations with topographic factors (Ayalew and Yamagishi, 2005; Ohlmacher and Davis, 2003; Zhou et al., 2002). In this study, spatial analysis was also carried out on the identified landslides and topographic factors derived from DEM. The topographic factors considered included elevation, slope gradient, aspect, and sub-watershed analysis.
As mentioned previously, the resolution of the pre-disaster DEM data is $40 \mathrm{~m}$ by $40 \mathrm{~m}$, which is much broader than the image's. Therefore, the analysis may not reveal fine details, but it should be able to provide helpful information in understanding possible connections between the landslides and topographic factors. For example, it is possible to understand whether landslides tend to occur at high or low altitudes by statistically examining the elevation distribution of landslides and comparing it with the background elevation distribution of the study site. Similar information can also be obtained by examining the slope gradient and aspect distributions. In addition, since heavy rainfall is the primary triggering factor of landslides in this study, drainage should be an important factor to explore. Therefore, sub-watershed analysis of DEM and its influence on landslides should also be considered. These issues are investigated and discussed subsequently.

Figure 7 displays the elevation distributions (histograms) of the background and the landslides as well as the scatter plot between the area and elevation of individual landslides. It appears that more than $80 \%$ of landslides occur at elevations between $500 \mathrm{~m}$ and $2000 \mathrm{~m}$. In terms of area, $85 \%$ of the landslide's average elevations are between $500 \mathrm{~m}$ and $2000 \mathrm{~m}$, which is greater than the background elevation distribution $(63 \%)$ in this range. It is also noticed from the scatter plot that there does not seem to be a direct correlation between the elevation and the size (area) of individual landslide. In Fig. 7d, the elevations of a few large-scale landslides are lower than $1500 \mathrm{~m}$, but since these are average elevations, their real elevation distributions may cover a wide range.

Similar analysis was also performed on slope aspect and gradient. Figure 8 displays the distribution of slope aspects of the background DEM and the identified landslides. Comparing the slope aspect distribution of the landslides with the background, the cumulative area of landslides in each slope aspect category is approximately proportional to the background. Based on this observation, slope aspect does not seem to be an important causative factor of landslides in this study case.

Previous studies (Ayalew and Yamagishi, 2005; Zhou et al., 2002) indicated that slope gradient has a more significant contribution than other topographic factors in landslides. In this study, spatial analysis was also performed on the landslides and slope gradients of sub-watersheds in the study site. Figure 9 shows the average slope gradients of the detected landslides and sub-watersheds (background) generated with spatial hydrology analysis of the pre-disaster DEM data.

Figure 10 displays the results of slope gradient analysis. Most of the landslides have average slope gradients in the range of 20 to $40^{\circ}$. There are few landslides in steep slope (gradient $\geq 50^{\circ}$ ) or in gentle regions in the study site. This is consistent with the results of Ayalew and Yamagishi (2005) and Zhou et al. (2002), although the majority of the background slope gradients are also between $20^{\circ}$ and $40^{\circ}$. However, based on the relationship between slope gradient and 


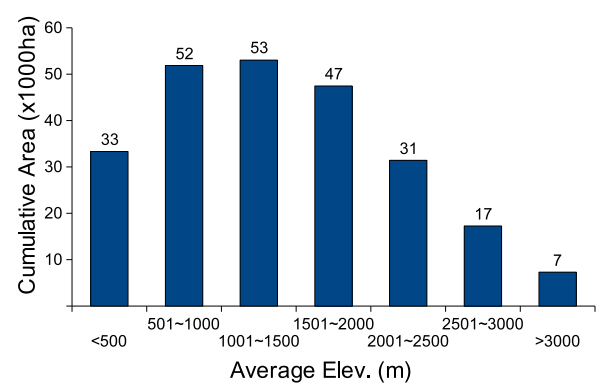

(a)

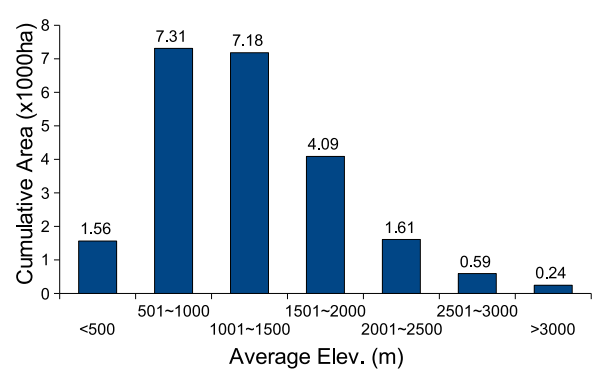

(c)

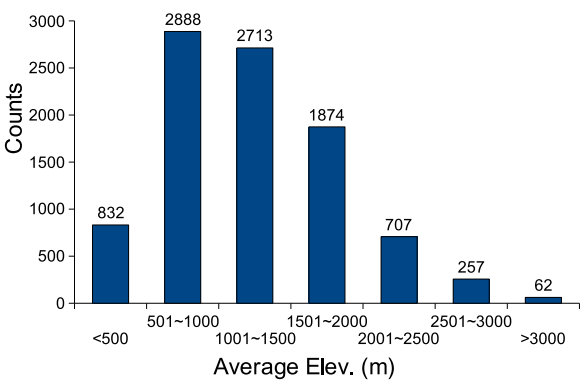

(b)

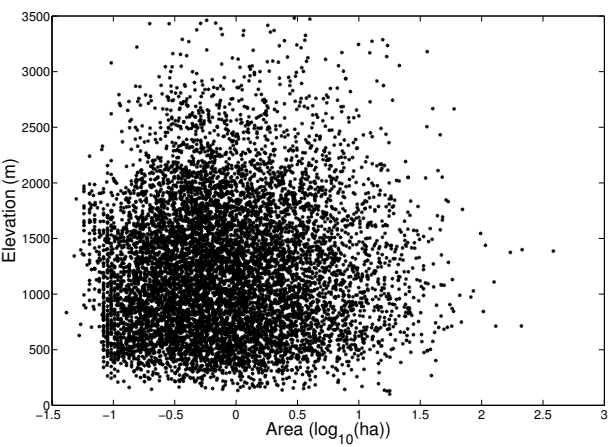

(d)

Fig. 7. Elevation analysis: (a) background elevation distribution; (b) average elevation histogram of landslides; (c) elevation distribution of cumulative landslide area; (d) scatter plot (elevation vs. area) of individual landslides. .

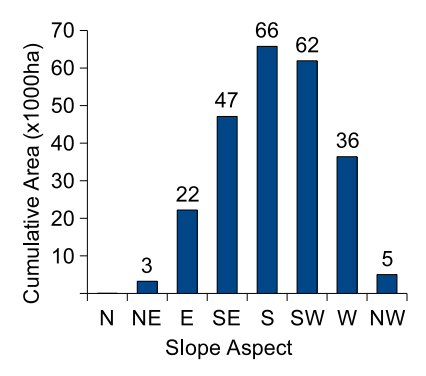

(a) background

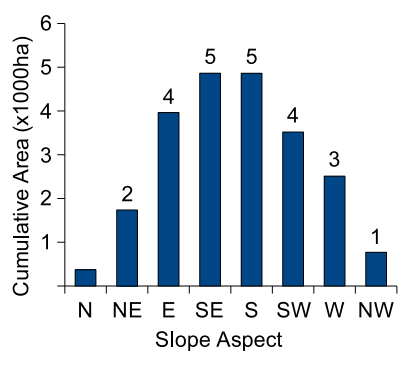

(b) landslides
Fig. 8. Slope aspect analysis.

area of individual landslides (Fig. 10d), large-area landslides in the study site do tend to occur on hills where their slope gradients are between $25^{\circ}$ and $35^{\circ}$, which agrees with the result of Zhou et al. (2002). In addition, it is also observed that landslides on very steep slopes are all small-scale landslides.

In addition to the sub-watershed polygons and their topographic attributes mentioned above, stream (drainage) networks in the entire basin of the study site were also generated with watershed delineation analysis of the DEM data. The identified landslides were overlaid with the derived stream networks to discern whether a slide was caused by headward erosion of a stream or gully. First of all, the occurrences of headward erosion do not seem to have specific topographic characteristics other than the understandable fact that they all originate from the heads of streams or gullies. The counts and areas of headward-erosion and other types of landslides exhibit notably different patterns as displayed in Fig. 11. There are less than $0.5 \%$ of identified landslides pertaining to headward erosion, but they account for more than $27 \%$ of the total landslide area. Apparently, headward-erosion type landslides tend to be large-scale ones. In fact, the top five largest landslides in the study site all appear to be headward erosion. A reasonable assumption is that the occurrence and the extent of a headward erosion may have to do with the combination of local hydrological and geological conditions. Taking the Xiaolin landslide as an example, the geology of this site was overhanging wedge combinations formed primarily by bedding planes and joints or small faults and the stream head area was covered by thick colluviums easy for water to infiltrate and saturate the wedge (Lee et al., 2009). However, due to the lack of complete and accurate geological data of the entire study site, these factors were not further investigated.

Among the landslides induced by Morakot in the study site, one was particularly deadly. It completely destroyed the Xiaolin village located by the Nanzixian Creek (in the left-middle of the study site) and claimed 500 human lives. Figure 12 displays the images and 3-D perspective views of the village and the landslide before and after the disaster. The pre-disaster image is cropped from a satellite image acquired 

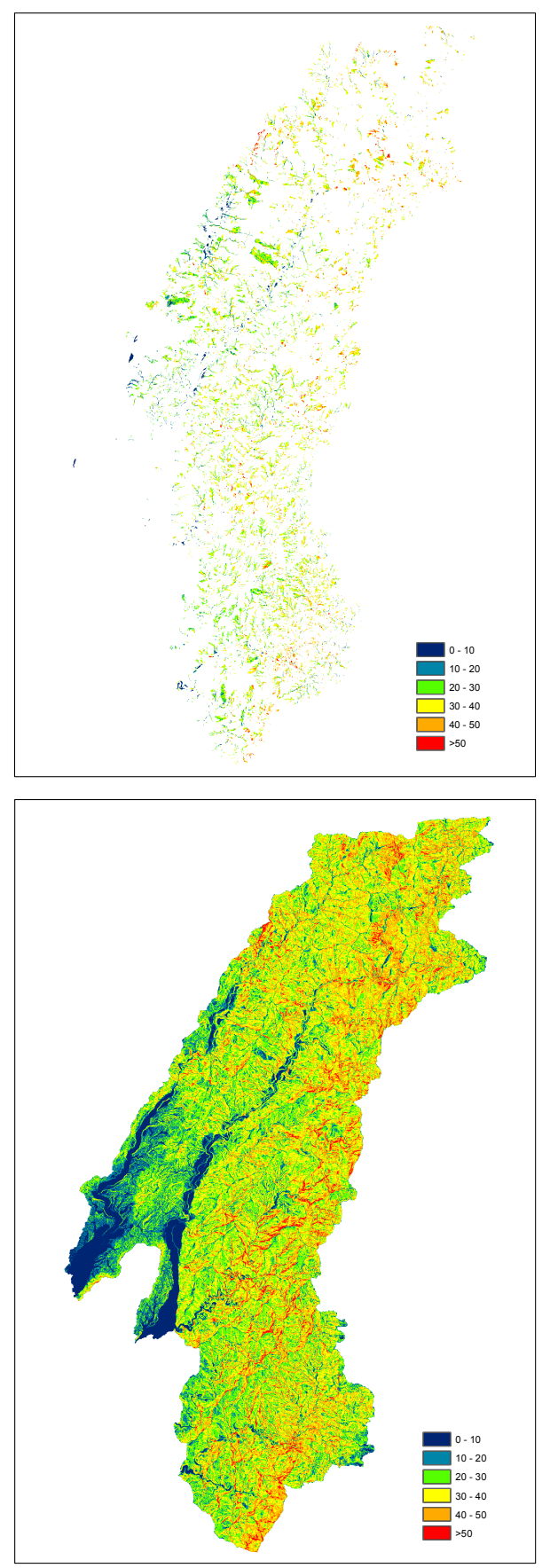

Fig. 9. Slope gradients of identified landslides and background watersheds.

on 15 January 2009, while the post-disaster image is a mosaic of aerial photographs taken several days after the typhoon. The 3-D (2.5-D) visualizations were generated by draping the images over high-resolution $(5 \mathrm{~m}$ by $5 \mathrm{~m}$ ) DEMs.

The Xiaolin landslide is the third largest one (about 211 ha) within the study site. From the images and visualizations shown in Fig. 12, it can be imagined that debris of mud, rubble and rocks cascaded down from the hill and deposited

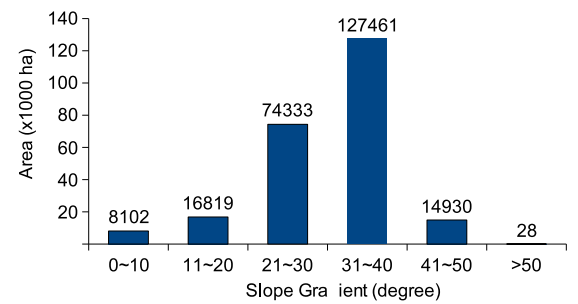

(a)

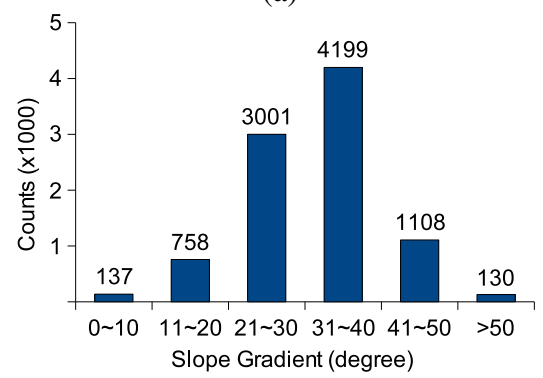

(b)

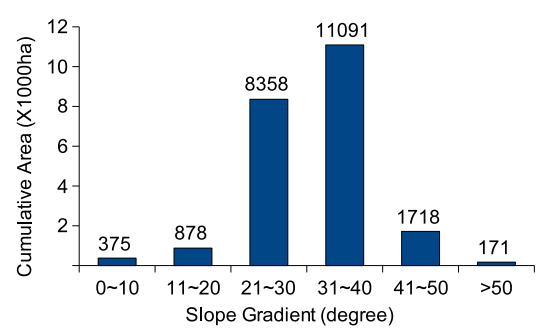

(c)

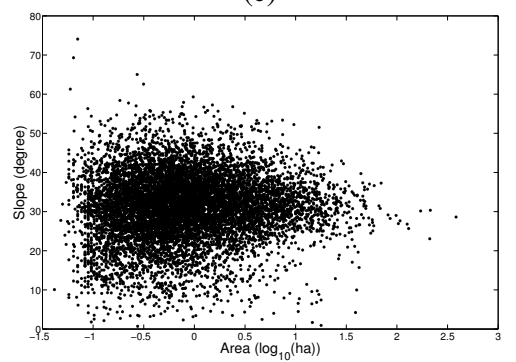

(d)

Fig. 10. Slope gradient analysis: (a) background slope gradient distribution; (b) slope gradient histogram of landslides; (c) slope gradient distribution of cumulative landslide areas; (d) scatter plot (slope gradient vs. area) of individual landslides.

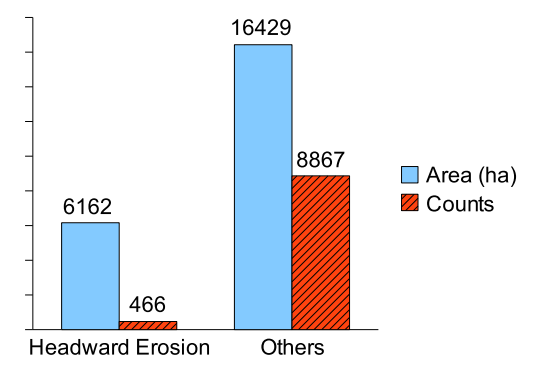

Fig. 11. Statistics of headward erosion. 

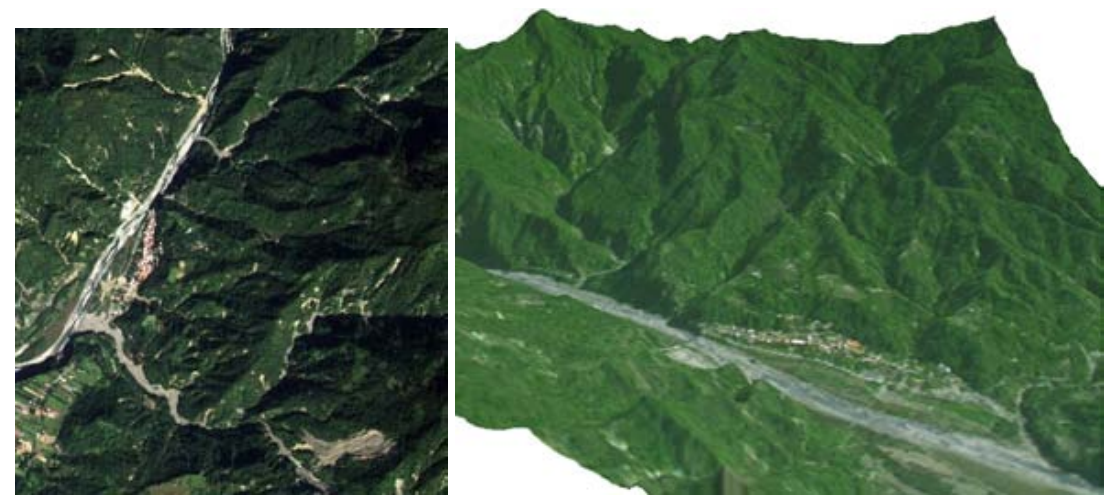

(a) pre-disaster image and 3D view
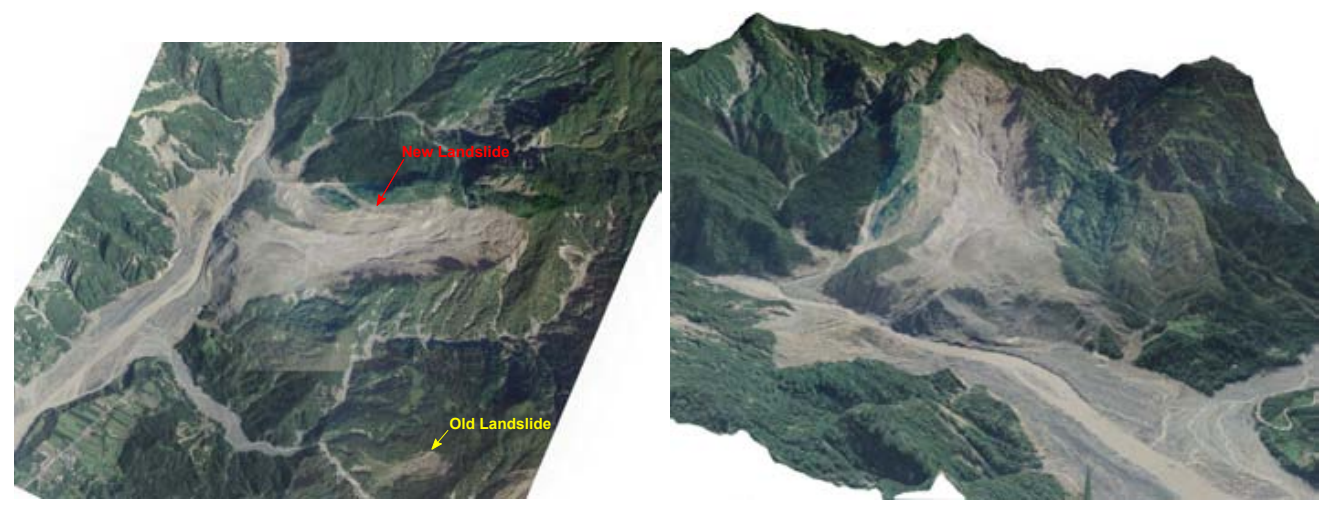

(b) post-disaster image and 3D view

Fig. 12. Images and 3-D visualizations of Xiaolin.

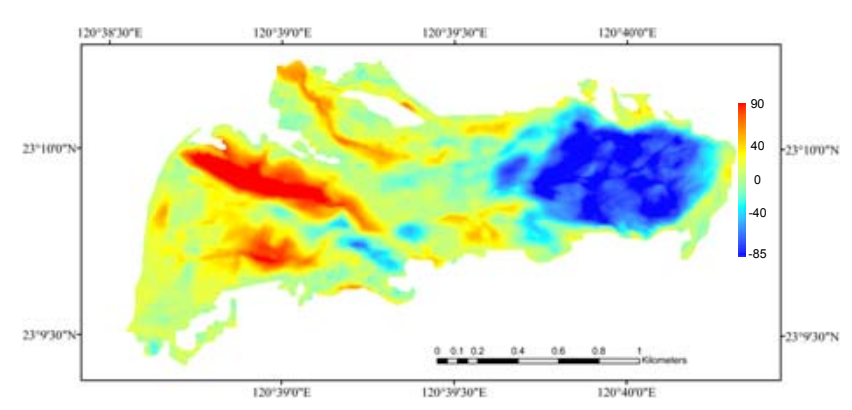

Fig. 13. Elevation differences of Xiaolin landslide.

in the foot, burying the village. In fact, the debris blocked the stream next to the village and formed a dam-up lake, which collapsed shortly thereafter, causing a flood and secondary debris flow. Apparently, the extreme rainfall was the primary triggering factor of this catastrophic landslide. According to a rain-gauge station in the same town, the cumulative precipitation of the area had reached $1700 \mathrm{~mm}$ before the landslide started. However, an intriguing observation is that there was an old landslide not far away from the disaster site (see the images in Fig. 12a and b), but it did not deteriorate after Typhoon Morakot. A preliminary inference is that the pre- vious landslide had washed off loose surface materials and stabilized the conditions of the site. Nevertheless, it will require thorough geotechnical and geological investigations to reach a more profound understanding of the circumstance.

Based on DEMs produced before and after the disaster, elevation differences of the Xiaolin landslide are calculated and displayed in Fig. 13, where negative and positive values indicate sliding and deposition depth, respectively. (Note that the values illustrated in Fig. 13 are not the ave thickness of the landslide, but vertical elevation changes computed by subtracting the pre-disaster DEM from the postdisaster DEM directly.) Both DEMs were generated from stereo aerial photographs. The pre-disaster DEM used for this analysis was extracted from a high-resolution $(5 \mathrm{~m}$ by $5 \mathrm{~m}$ ) national DEM project in 2008, which has better resolution and is more updated than the $40 \mathrm{~m}$ resolution one used for topographic analysis of the entire study site mentioned previously. As displayed in Fig. 13, the deepest collapse is about $85 \mathrm{~m}$ with an average depth of $40 \mathrm{~m}$, while the thickest deposition is about $90 \mathrm{~m}$. The volume of slide is estimated to be 2.658 million $\mathrm{m}^{3}$. The estimations have been compared with another independent study (Lee et al., 2009) and both investigations seem to reach similar results. 


\section{Conclusions}

This study utilized remote sensing and spatial analysis to investigate landslide hazards caused by the 2009 Typhoon Morakot in southern Taiwan. Multi-temporal satellite images were used as the main dataset for landslide detection. Sophisticated and rigorous orthorectification algorithms and radiometric corrections were applied to the satellite images before the analysis. Landslides were identified with a systematic procedure including NDVI filtering, CVA, and interactive examination. The NDVI filtering detected possible landslides automatically by comparing NDVI values calculated from the pre- and post-disaster satellite images with pre-set thresholds, while CVA identified changed and unchanged pixels from change vectors calculated from different spectral bands. The NDVI filtering result was integrated with changed pixels identified in CVA and categorized as possible landslides by spatial Boolean operations to minimize omissions. They were then interactively examined and edited if necessary to produce a complete landslide map. As a result, 9333 landslides (total area of 22590 ha) were detected. Afterward, spatial analysis was performed on the identified landslides and topographic factors. Based on the spatial analysis, most of the landslides in the study site are small-scale (less than 1 ha in terms of area) and large-area landslides are mostly pertaining to headward erosion. Topographic analysis results indicate that most of the landslide sites have average elevations between $500 \mathrm{~m}$ and $2000 \mathrm{~m}$ with average slope gradients in the range of $20^{\circ}$ to $40^{\circ}$, and large-area landslides all occur on hills with average slope gradients between $25^{\circ}$ and $35^{\circ}$. In addition to the overall spatial analysis, a particularly catastrophic landslide that completely destroyed a riverside village was further investigated with aerial photographs and high-resolution DEM data. The volume of this slide is estimated to be more than 2.6 million $\mathrm{m}^{3}$ with an average depth of $40 \mathrm{~m}$.

The post-disaster assessment of landslides produced in this study provides comprehensive insights into the natural hazards caused by Typhoon Morakot in the study site. It produced a complete and reasonably accurate landslide map. Statistical and spatial analysis of the landslides with topographic factors discovered important characteristics of the hazards. The results are valuable for decision and policy support in post-disaster reconstruction. They are also helpful in developing effective strategies to reduce the risks of future damages to infrastructure and properties. In addition, this study has also successfully established a feasible framework for employing remote sensing and spatial analysis in hazard investigation.

Acknowledgements. The authors would like to thank RealWorld Engineering Consultants, Inc. for supplying aerial photographs. Some of the data used in this study were provided by the Chinese Institute of Civil and Hydraulic Engineering and other agencies.
A special thanks also goes to J. K. Liu of the Industrial Technology Research Institute (ITRI), Taiwan, for comparing his notes with ours on the Xiaolin landslide.

Edited by: K.-T. Chang

Reviewed by: two anonymous referees

\section{References}

Anderson, K. and Milton, E. J.: Characterisation of the apparent reflectance of a concrete calibration surface over different time scales, in: The 9th International Symposium on Physical Measurements and Signatures in Remote Sensing (ISPMSRS), Beijing, China, 2005.

Ayalew, L. and Yamagishi, H.: The application of GIS-based logistic regression for landslide susceptibility mapping in the KakudaYahiko Mountains, Central Japan, Geomorphology, 65, 15-31, 2005.

Canty, M. J., Nielsen, A. A., and Schmidt, M.: Automatic Radiometric Normalization of Multitemporal Satellite Imagery, Remote Sens. Environ., 91, 441-451, 2004.

Chang, C.-P., Kuo, H.-C., and Yang, Y.-T.: Can We Blame Typhoon Morakot on Global Warming?, in: Proc. 5th International OceanAtmosphere Conference, Taipei, Taiwan, 1, p. 3, 2010.

Chen, L. C. and Chang, L. Y.: Three dimensional positioning using SPOT stereostrips with sparse control, J. Surv. Eng.-ASCE, 124, 63-72, 1998.

Chen, L. C. and Teo, T. A.: Rigorous generation of digital orthophotos from EROS-A high resolution satellite images, International Archives of Photogrammetry, Remote Sensing and Spatial Information Sciences, 34, 620-625, 2002.

Chen, L. C., Teo, T. A., and Rau, J. Y.: Adaptive Patch Projection for the Generation of Orthophotos from Satellite Images, Photogramm. Eng. Rem. S., 71, 1321-1327, 2005.

Du, Y., Teillet, P. M., and Cihlar, J.: Radiometric normalization of multitemporal high-resolution satellite images with quality control for land cover change detection, Remote Sens. Environ., 82, 123-134, 2002.

Gomez, C., Delacourt, C., Allemand, P., Ledru, P., and Wackerle, R.: Using ASTER remote sensing data set for geological mapping in Namibia, Phys. Chem. Earth, 30, 97-108, 2005.

Kasischke, R.: Change vector analysis: a technique for the multispectral monitoring of land cover and condition, Int. J. Remote Sens., 19, 411-426, 1998.

Kim, T., Shin, D., and Lee, Y. R.: Development of robust algorithm for transformation of a 3D object onto 2D image point for linear pushbroom imagery, Photogramm. Eng. Rem. S., 67, 449-452, 2001.

Lambin, E. F. and Strahlers, A. H.: Change-vector analysis in multitemporal space: A tool to detect and categorize land-cover change processes using high temporal-resolution satellite data, Remote Sens. Environ., 48, 231-244, 1994.

Lee, C. T., Dong, J. J., and Lin, M. L.: Geological Investigation on the Catastrophic Landslide in Siaolin Village, Southern Taiwan, Sino-Geotechnics, 122, 87-94, 2009 (in Chinese with English abstract).

Li, S. and Niu, Z.: Apparent Reflectance and Its Applications Using Resourcesat-1 Remote Sensing Data, in: SPIE Proceeding of Geoinformatics 2006: Remotely Sensed Data and Information, 
edited by: Zhang, L. and Chen, X., 6419, 64190D-1-64190D-5, Wuhan, China, 2006.

Metternicht, G., Hurni, L., and Gogu, R.: Remote sensing of landslides: An analysis of the potential contribution to geo-spatial systems for hazard assessment in mountainous environments, Remote Sens. Environ., 98, 284-303, 2005.

Mikhail, E. M. and Ackerman, F.: Observations and Least Squares, University Press of America, New York, USA, 1982.

NDPPC: Disaster Response Disposition Report of Typhoon Morakot, Tech. Rep. No. 74, National Disaster Prevention and Protection Commission, Taiwan (ROC), available at: http://www.ndppc.nat.gov.tw/ContentDetail.aspx?MID= $164 \&$ UID $=164 \& C I D=2747 \& \mathrm{PID}=164$ (last access: 12 January 2010, 2009 (in Chinese).

Nguyen, H. V. and Chen, Y.-L.: WRF Simulation of a TC-Induced Recored-Breaking Heavy Rainfall Event over Taiwan, in: Proc. 5th International Ocean-Atmosphere Conference, Taipei, Taiwan, 1, 178-183, 2010.

Nichol, J. and Wong, M. S.: Satellite remote sensing for detailed landslide inventories using change detection and image fusion, Int. J. Remote Sens., 26, 1913-1926, 2005.

Ohlmacher, G. C. and Davis, J. C.: Using multiple logistic regression and GIS technology to predict landslide hazard in northeast Kansas, USA, Eng. Geol., 69, 331-343, 2003.
Peduzzi, P.: Landslides and vegetation cover in the 2005 North Pakistan earthquake: a GIS and statistical quantitative approach, Nat. Hazards Earth Syst. Sci., 10, 623-640, doi:10.5194/nhess10-623-2010, 2010.

Rau, J. Y., Chang, L. Y., Teo, T. A., Hsu, K., Chen, J. Y., Chen, L. C., Chen, A. J., and Chen, K. S.: An Operational Multi-Sensor Geocoded Production System for Earth Resources Satellite Images, in: Proceedings of the 5th Int. Symposium on the Reducing Cost of Spacecraft and Ground Systems and Operations (RCSGSO), Pasadena, CA USA, 2003.

Sarkar, S. and Kanungo, D. P.: An Integrated Approach for Landslide Susceptibility Mapping Using Remote Sensing and GIS, Photogramm. Eng. Rem. S., 70, 617-625, 2004.

Schott, J. R., Salvaggio, C., and Volchok, W. J.: Radiometric scene normalization using pseudoinvariant features, Remote Sens. Environ., 26, 1-16, 1988.

Toutin, T.: Block Bundle Adjustment of IKONOS In-Track Image, Int. J. Remote Sens., 24, 851-857, 2003.

Tsai, F. and Chen, L. C.: Long-Term Landcover Monitoring and Disaster Assessment in the Shimen Reservoir Watershed Using Satellite Images, in: 13th CeRES International Symposium on Remote Sensing, Chiba, Japan, 2007.

Zhou, C., Lee, C., Li, J., and Xu, Z.: On the spatial relationship between landslides and causative factors on Lantau Island, Hong Kong, Geomorphology, 43, 197-207, 2002. 